\title{
Solid-Phase Synthesis of a Special Phosphorylated Peptide as a Biomarker for LC-MS/MS Detection for OPNA Exposure
}

\author{
Xinhai Lia,b \\ Ling Yuan ${ }^{\mathrm{a}, \mathrm{b}}$ \\ Qinggang Wang ${ }^{c}$ \\ Longhui Lianga,b \\ Guilan Huanga,b \\ Shilei Liu*a,b \\ Jingquan Liu*a \\ a State Key Laboratory of NBC Protection for Civilian, Beijing, \\ 102205, P. R. of China \\ liushilei402@263.net \\ ${ }^{\mathrm{b}}$ Laboratory of Analytical Chemistry, Research Institute of \\ Chemical Defence, Beijing, 102205, P. R. of China \\ Key Laboratory of Biobased Materials, Qingdao Institute of \\ Bioenergy and Bioprocess Technology, Chinese Academy of \\ Sciences, 189 Songling Road, 266101 Qingdao, P. R. of China
}

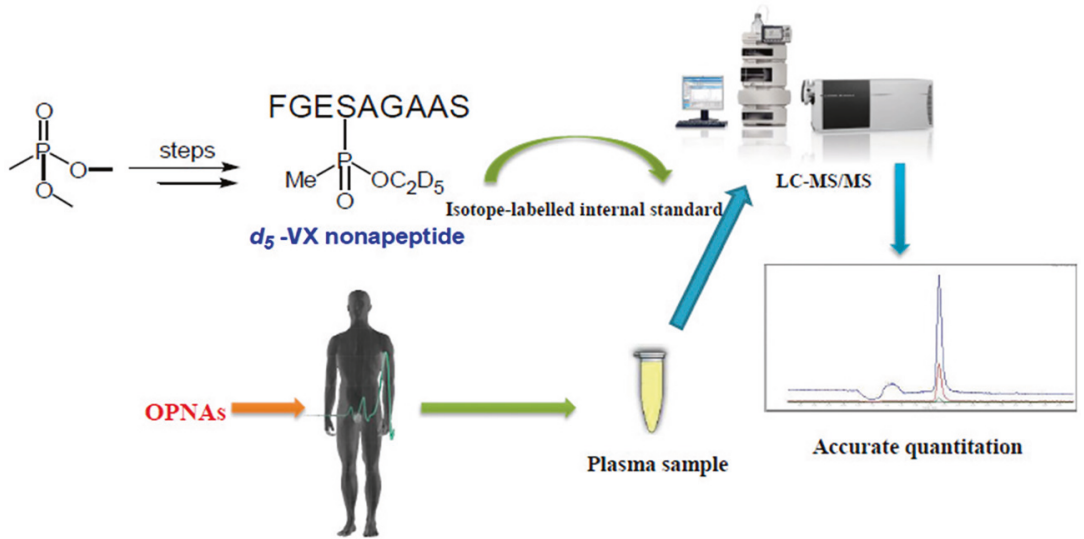

Received: 23.10.2016

Accepted after revision: 13.12 .2016

Published online: 01.03.2017

DOI: 10.1055/s-0036-1588691; Art ID: st-2016-w0710-|

Abstract A synthesis of $d_{5}-\mathrm{VX}$ adducted nonapeptide via solid-phase approach has been developed. The $d_{5}-\mathrm{VX}$ peptide could be used as the isotope-labeled internal standard for LC-MS/MS detecting the BuChEOPNA biomarkers. The Kaiser test was utilized to ensure the right connections of all of the amino acids. This method offers an access to the synthesis and detection of other phosphorylated nonapeptides.

Key words $d_{5}-\mathrm{VX}$, solid-phase, nonapeptide, isotope label, BuChEOPNA adducts

Organophosphorus nerve agents (OPNAs) are typical toxic chemical agents which could inhibit the enzymatic activity of cholinesterase (ChE). ${ }^{1}$ The structures of three commonly known OPNAs are shown in Figure 1. Because of their high toxicity and illegal uses in terrorist attacks such as sarin or its similar compounds attack in Tokyo, Matsumoto, and Syrian, ${ }^{2}$ OPNAs are still one type of the most potential threats to human life and modern societies. Therefore, an easy and reliable method for the retrospective detection of OPNA exposure is of great demand. Several methods have been developed for the detection of OPNA exposure through mass spectrometry technology, such as the direct analysis of OPNA hydrolysis products (e.g., $O$-alkyl methylphosphonic acids) in vivo ${ }^{3}$ and 'biomarkers' analysis of the OPNA combined proteins. Because of the short lifetime (ca. $90 \%$ excretion in urinary within $2-3 \mathrm{~d})^{4}$ of the OPNA hydrolysis products existing in vivo, the adducted biomarkers analysis method has become a more reliable and efficient approach. Here, we report a $d_{5}$-VX biomarker via the solid-phase synthesis as the internal standard for the mass spectrometric detection of OPNA exposure.

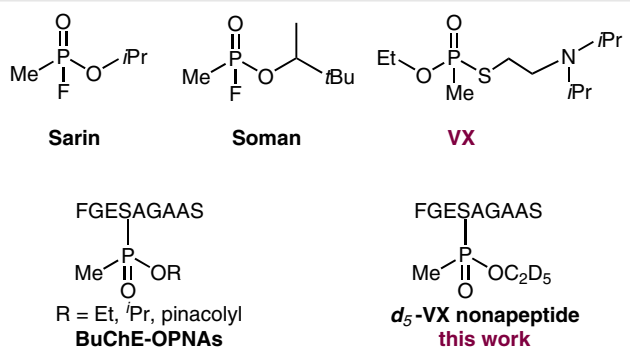

Figure 1 Structures of prominent organophosphorus nerve agents, their nonapeptides derived from the pepsin digestion of the BChEOPNA adducts, and the $d_{5}$-VX nonapeptide

As a kind of the ChE, the butyrylcholine esterase (BuChE) which combined with OPNAs has a lifetime over two weeks and mainly exists in blood. ${ }^{5}$ Due to the ability of highly selective combining with serine-198 residue of $\mathrm{Bu}-$ ChE by covalent bond and easy material availability, the BuChE-OPNA adducts were chosen to be the appropriate in vivo biomarkers for the retrospective analysis for OPNA post exposure. ${ }^{6}$ The biomarkers can be converted into the phosphorylated nonapeptide ${ }^{7}$ compounds with similar structures through the pepsin digestion. Currently, the dechromatography with isotope dilution tandem mass spectrometric (LC-MS/MS) quantitative detection of the phosphorylated nonapeptide (Figure 1 ). Although the analysis of the in vivo biomarker in blood sample plays an important role in forensic investigations of the alleged use of nerve agents currently, to the best of our knowledge, there is no literature reporting the synthesis method of the isotope-labeled internal standard nonapeptides. Herein, we envisioned to synthesize a brand new $d_{5}$-VX nonapeptide (Figveloped method was based on high-performance liquid 
ure 1) which could be used as the isotope-labeled internal standard of BuChE-OPNA biomarkers via LC-MS/MS detecting.

The synthetic procedures of the $d_{5}$-VX adducted nonapeptide are presented in Scheme 1. As the starting material, dimethyl methylphosphonate was treated with excess equivalent sulfoxide chloride at $140^{\circ} \mathrm{C}$ for six hours, affording methylphosphonic dichloride $2^{8}$ in the $90 \%$ yield. Subsequent monoesterification with $d_{6}$-ethanol in triethylamine led to $d_{5}$-ethyl methylphosphonic monocloridate $\mathbf{3}$ in 36\% yield. ${ }^{9}$ The chemical 3 must be purified by careful distillation under vacuum to prevent the undesired polymerization. $d_{5}$-Fmoc-serine( $O$-ethyl methylphosphonate) benzyl ester $(4)^{10}$ was obtained in the $60 \%$ yield by reacting with the protected serine $\mathbf{6}$ in the presence of 4-dimethylaminopyridine (DMAP) and triethylamine. Four equivalents of the intermediate $\mathbf{3}$ were used during the esterification because of the low reactivity. Finally, target molecule $\mathbf{5}$, which is the important precursor before solid-phase synthesis, was formed by the Pd/C hydrogenation of $\mathbf{4}^{10}$ with $80 \%$ yield.

The target compound $\mathbf{7}$ was synthesized via the solidphase peptide synthesis on a Fmoc-Ser ( $t$-Bu)-Wang resin. Compared with the method reported before, ${ }^{10}$ it takes less time for the resin elution to obtain the target peptide and the method could be used in practical synthesis. The synthesis was done manually from $\mathrm{C}$-terminal to $\mathrm{N}$-terminal to enhance the coupling efficiency. The peptides were synthesized using Fmoc chemistry and HBTU/DIPEA activation. Piperidine/DMF (25\%) was used to deprotect the Fmoc group. The rest of the amino acid residues were induced onto the resin in sequence by HBTU/DIPEA activation. The Kaiser test was used to ensure the connection with the correct amino acid residue upon every step. After this point, cleavage from the resin was achieved by treating the peptide resin with the solution containing 68.5\% TFA, 10\% 1,2-
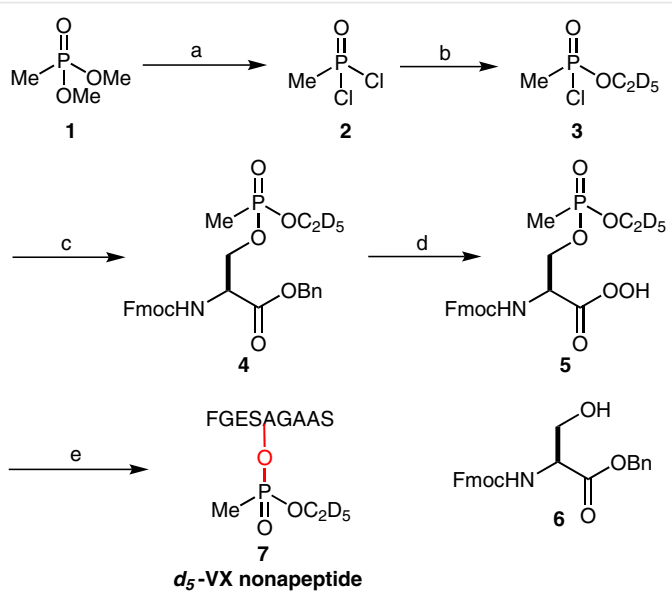

Scheme 1 Synthesis route of $d_{5}-\mathrm{VX}$ nonapeptide. Reagents and conditions: (a) $\mathrm{SOCl}_{2}$ ( 2.5 equiv), $140{ }^{\circ} \mathrm{C}, 90 \%$ yield; (b) $\mathrm{C}_{2} \mathrm{D}_{5} \mathrm{OD}$ ( 1 eqiuv), $\mathrm{Et}_{3} \mathrm{~N}$, benzene, $36 \%$ yield; (c) reagent 6 ( 0.25 equiv), $\mathrm{Et}_{3} \mathrm{~N}$, DMAP, benzene, $0{ }^{\circ} \mathrm{C}, 75 \%$ yield; (d) $\mathrm{H}_{2}, 10 \% \mathrm{Pd} / \mathrm{C}$, THF-MeOH, $80 \%$ yield; (e) manual solid-phase peptide synthesis procedure

ethanedithiol, $10 \%$ thioanisole, $5 \%$ phenol, $3.5 \%$ double-distilled water, and $1 \%$ triisopropylsilane for three hours at room temperature.

The crude product of the phosphorylated peptide, which could be precipitated by anhydrous diethyl ether, was further purified by reversed-phase HPLC on a C18 column $(0.05 \%$ TFA-water- $2 \% \mathrm{MeCN})$. Peptide purity was $>90 \%$ by analysis of HPLC-DAD. It was also verified by NMR spectroscopy and high-resolution mass spectrometry. HRMS (ESI+) data showed the molecular weight 907.3968 $\left(\mathrm{C}_{36} \mathrm{H}_{51} \mathrm{D}_{5} \mathrm{PN}_{9} \mathrm{O}_{16}\right)$, and the ${ }^{1} \mathrm{H}$ NMR $\left(599.7 \mathrm{MHz}, \mathrm{D}_{2} \mathrm{O}\right)$ data were shown as follows: $\delta=1.28(\mathrm{t}, J=7.4 \mathrm{~Hz}, 9 \mathrm{H}), 1.47(\mathrm{~d}$, $\left.{ }^{2} J_{\mathrm{H}-\mathrm{C}-\mathrm{P}}=17.6 \mathrm{~Hz}, 3 \mathrm{H}\right), 1.80-2.11(\mathrm{~m}, 6 \mathrm{H}), 2.37(\mathrm{t}, J=7.1 \mathrm{~Hz}$, $2 \mathrm{H}), 3.12(\mathrm{~m}, 3 \mathrm{H}), 3.75-3.88(\mathrm{~m}, 6 \mathrm{H}), 4.20-4.35(\mathrm{~m}, 9 \mathrm{H})$, $4.55(\mathrm{~s}, 1 \mathrm{H}), 7.18(\mathrm{~d}, J=7.2 \mathrm{~Hz}, 2 \mathrm{H}), 7.26-7.31(\mathrm{~m}, 3 \mathrm{H})$.

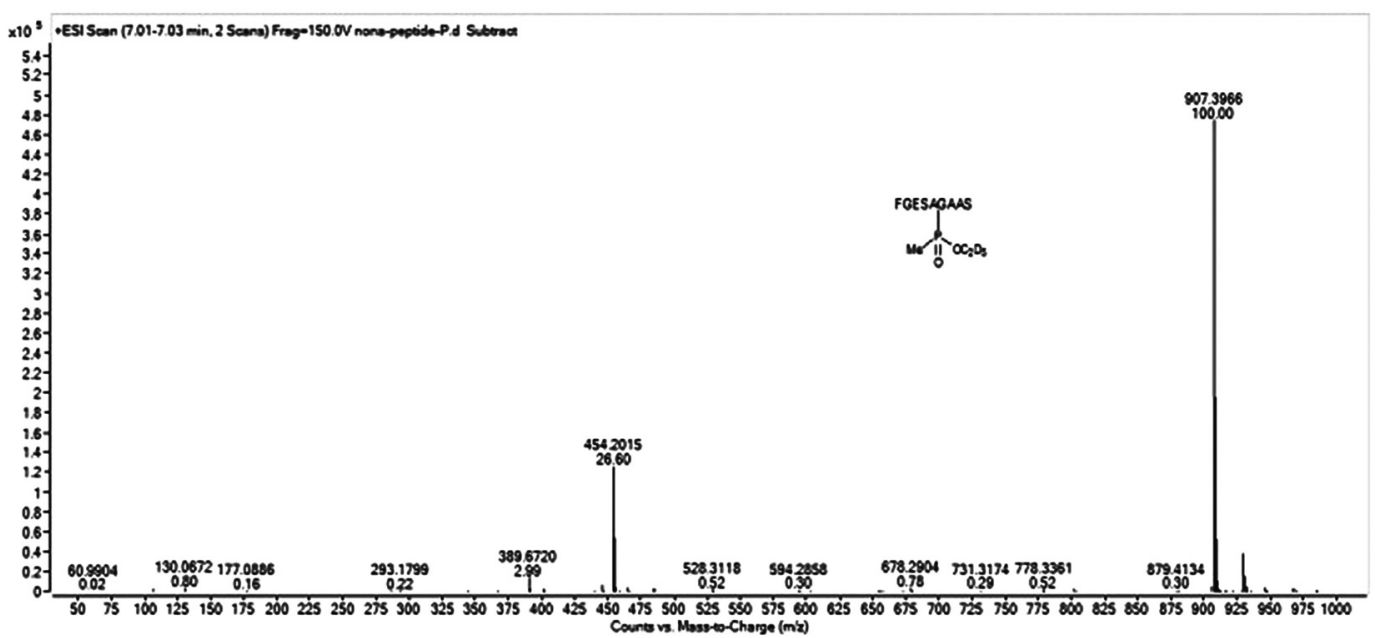

Figure 2 LC-HRMS of the $d_{5}$-VX adducted nonapeptide. 
The fragmentation of the $d_{5}$-VX adducted nonapeptide (Figure 2 and Figure 3) was observed by precursor-to-product ion transitions monitored using multiple reaction monitoring (MRM). The protonated peptide-adduct fragments showed losses of the adducted agent, the C-terminal serine and the $\mathrm{C}$-terminal alanine. It showed the same fragmentation pattern as the VX-BuChE nonapeptide. ${ }^{7 c}$ As shown in the Figure 3, the precursor ion for the chemical $7(\mathrm{~m} / z=$ 907.3968) exhibited product ions derived from a loss of 129.0604 Da which corresponds to the loss of the $d_{5}$-VX moiety $(m / z=778.3364)$; further losses of the terminal serine $(m / z=673.2932)$, and the alanine $(m / z=602.2554)$ residue were also exhibited.

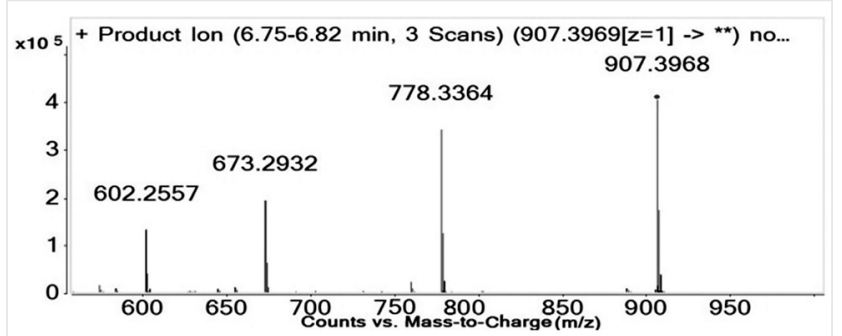

Figure 3 Product ion scan of protonated $d_{5}$-VX -adducted nonapeptide

In summary, a synthesis approach of $d_{5}$-VX adducted nonapeptide via solid phase has been developed. ${ }^{11}$ The MS/MS fracture manner of the $d_{5}$-VX nonapeptide is the same as that of VX-BuChE nonapeptide. ${ }^{7 c}$ So the brand new compound $d_{5}$-VX peptide could be used as the isotope-labeled internal standard for LC-MS/MS-detecting BuChEOPNA adducts. Additionally, the synthesis material $d_{6}$-Ethanol used in the procedure has a much more easier availability and cheaper price than the deuterated amino acid used in the former literature. ${ }^{5}$ This method may also find applications in the synthesis and detection of other phosphorylated nonapeptides.

\section{Acknowledgment}

The work was supported by the State Key Laboratory of NBC Protection for Civilian (grant no. SKLNBC2014-06).

\section{Supporting Information}

Supporting information for this article is available online at https://doi.org/10.1055/s-0036-1588691.

\section{References}

(1) (a) John, H.; Worek, F. Anal. Bioanal. Chem. 2008, 391, 97. (b) Fidder, A.; Hulst, A. G.; Noort, D.; de Ruiter, R.; van der Schans, M. J.; Benschop, H. P.; Langenberg, J. P. Chem. Res. Toxicol. 2002, 15, 582.
(2) (a) Morita, H.; Yanagisawa, N.; Nakajima, T.; Shimizu, M.; Hirabayashi, H.; Okudera, H.; Nohara, M.; Midorikawa, Y.; Mimura, S. Lancet 1995, 346, 290. (b) Nakajima, T.; Ohta, S.; Morita, H.; Midorikawa, Y.; Mimura, S.; Yanagisawa, N. J. Epidemiol. 1998, 8, 33. (c) Suzuki, T.; Morita, H.; Ono, K.; Maekawa, K.; Nagai, R.; Yazaki, Y. Lancet 1995, 345, 980.

(3) (a) Shih, M. L.; Smith, J. R.; McMonagle, J. D.; Dolzine, T. W.; Gresham, V. C. Biol. Mass Spectrom. 1991, 20, 717. (b) Black, R. M.; Clarke, R. J.; Read, R. W.; Reid, M. T. J. J. Chromatogr. A 1994, 662, 301. (c) Tørnes, J. A. Rapid. Commun. Mass Spectrom. 1996, 10, 878. (d) Black, R. M.; Read, R. W. J. Chromatogr. A 1997, 759, 79. (e) Black, R. M.; Read, R. W. J. Chromatogr. A 1998, 794, 233. (f) Noort, D.; Hulst, A. G.; Platenburg, D. H. J. M.; Polhuijs, M.; Benschop, H. P. Arch. Toxicol. 1998, 72, 671.

(4) Riches, J.; Morton, I.; Read, R. W.; Black, R. M. J. Chromatogr. B 2005, 816, 251.

(5) (a) Bao, Y.; Liu, Q.; Chen, J.; Lin, Y.; Wu, B.; Xie, J.J. Chromatogr. A 2012, 1229, 164. (b) Noort, D.; Benschop, H. P.; Black, R. M. Toxicol. Appl. Pharmacol. 2002, 184, 116.

(6) Abney Carter, W.; Knaack, L. S. J.; Ali, I. A. A.; Johnson, C. R. Chem. Res. Toxicol. 2013, 26, 775.

(7) (a) Knaack, S. J.; Zhou, Y.; Abney, W. C.; Jacob, T. J.; Prezioso, M. S.; Hardy, K.; Lemire, W. S.; Thomas, J.; Johnson, C. R. Anal. Chem. 2012, 84, 9470. (b) Carter, D. M.; Crow, S. B.; Pantazides, G. B.; Watson, M. C.; Thomas, D. J.; Blake, T. A.; Johnson, C. R. Anal. Chem. 2013, 85, 11106. (c) Sporty, L. S. J.; Lemire, W. S.; Jakubowski, M. E.; Renner, A. J.; Evans, A. R.; Williams, F. R.; Schmidt, G. J.; van der Schans, J. M.; Noort, D.; Johnson, C. R. Anal. Chem. 2010, 82, 6593.

(8) (a) He, Z.-J.; Wang, Y.-M.; Tang, C.-C. Phosphorus, Sulfur Silicon Relat. Elem. 1997, 127, 59. (b) Bennet, A. J.; Kovach, I.; Bibbs, J. A. J. Am. Chem. Soc. 1989, 111, 6224.

(9) (a) Hudson, R. F.; Keay, L. J. Chem. Soc. 1956, 2463. (b) Struck, R. F. J. Med. Chem. 1966, 9, 231.

(10) MacDonald, M.; Lanier, M.; Cashman, J. Synlett 2010, 1951.

(11) The target compound $d_{5}$-VX adducted nonapeptide was synthesized via the solid-phase peptide synthesis manually from Cterminal to $\mathrm{N}$-terminal to enhance the coupling efficiency. The peptides were synthesized using Fmoc chemistry on a Fmoc-Ser $(t-\mathrm{Bu})$-Wang resin and HBTU/DIPEA activation. Piperidine-DMF (25\%) was used to deprotect the Fmoc group. The rest of the amino acid residues were induced onto the resin in sequence by HBTU/DIPEA activation. The Kaiser test was used to ensure the connection with right amino acid residue upon every step. After this point, cleavage from the resin was achieved by treating the peptide resin with the solution containing $68.5 \%$ TFA, 10\% 1,2ethanedithiol, $10 \%$ thioanisole, $5 \%$ phenol, $3.5 \%$ double-distilled water, and $1 \%$ triisopropylsilane for $3 \mathrm{~h}$ at r.t. The crude product of the phosphorylated peptide which could be precipitated by anhydrous $\mathrm{Et}_{2} \mathrm{O}$ was further purified by reversed-phase HPLC on a 18 column $(0.05 \%$ TFA-water- $2 \% \mathrm{MeCN})$. Peptide purity was $>90 \%$ by analysis of HPLC-DAD. It was also verified by NMR and high-resolution MS. HRMS (ESI+): $\mathrm{m} / z$ found for $\mathrm{C}_{36} \mathrm{H}_{51} \mathrm{D}_{5} \mathrm{PN}_{9} \mathrm{O}_{16}$ : 907.3968. ${ }^{1} \mathrm{H}$ NMR (599.7 MHz, $\left.\mathrm{D}_{2} \mathrm{O}\right): \delta=1.28$ $(\mathrm{t}, J=7.4 \mathrm{~Hz}, 9 \mathrm{H}), 1.47\left(\mathrm{~d},{ }^{2} \mathrm{~J}_{\mathrm{H}-\mathrm{C}-\mathrm{P}}=17.6 \mathrm{~Hz}, 3 \mathrm{H}\right), 1.80-2.11(\mathrm{~m}, 6$ $\mathrm{H}), 2.37(\mathrm{t}, J=7.1 \mathrm{~Hz}, 2 \mathrm{H}), 3.12(\mathrm{~m}, 3 \mathrm{H}), 3.75-3.88(\mathrm{~m}, 6 \mathrm{H})$, $4.20-4.35(\mathrm{~m}, 9 \mathrm{H}), 4.55(\mathrm{~s}, 1 \mathrm{H}), 7.18(\mathrm{~d}, J=7.2 \mathrm{~Hz}, 2 \mathrm{H}), 7.26-$ $7.31(\mathrm{~m}, 3 \mathrm{H}) .{ }^{13} \mathrm{C}\left\{{ }^{1} \mathrm{H}\right\}$ NMR $\left(150.8 \mathrm{MHz}, \mathrm{D}_{2} \mathrm{O}\right): \delta=177.1,175.0$, 174.7, 174.6, 173.5, 173.3, 170.9, 170.7, 169.8, 169.6, 133.6, $129.3,129.1,128.0,64.2,64.1,61.2,61.1,55.1,54.4,53.45$, 53.40, 53.35, 53.1, 49.9, 49.5, 49.4, 42.2, 36.7, 30.0, 26.1, 16.7, $16,4,9.4,8.5 .{ }^{31} \mathrm{P}\left\{{ }^{1} \mathrm{H}\right\}$ NMR $\left(242.8 \mathrm{MHz}, \mathrm{D}_{2} \mathrm{O}\right): \delta=35.9$. 